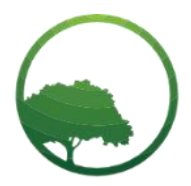

Research in Business \& Social Science

IJRBS VOL 10 NO 4 ISSN: 2147-4478

\title{
Impacts of online social support and perceived value in influential travel blogs

\author{
Wanching Chang ${ }^{(a)}$ (D) Ren-Fang Chao ${ }^{(b) *(1)}$ Grace C.L Chien ${ }^{(c)}$ \\ (b) Professor, Department of Leisure Management, I-Shou University, No.1, Sec. 1, Syuecheng Rd., Dashu District, Kaohsiung City 84001,Taiwan \\ ${ }^{(c)}$ Assistant Professor, Department of Hospitality Management, I-Shou University, No.1, Sec. 1, Syuecheng Rd., Dashu District, Kaohsiung City \\ 84001, Taiwan
} \\ (a) Assistant Professor, Department of Tourism, I-Shou University, No.1, Sec. 1, Syuecheng Rd., Dashu District, Kaohsiung City 84001,Taiwan
}

\author{
A R T I C L E IN F O \\ Article history: \\ Received 19 May 2021 \\ Received in rev. form 08 June 2021 \\ Accepted 10 June 2021 \\ Keywords: \\ Influential Travel Bloggers, Sense of \\ Virtual Community (SOVC), Online \\ Social Support, Perceived Value, \\ Social Media \\ JEL Classification: \\ Z33, O35
}

\begin{abstract}
A B S T R A C T
As a result of exponential growth in the popularity of blogging, travel blogs have demonstrated their enormous marketing potential, and have become an increasingly important mechanism for exchanging information among tourists. The present study modeled online social support and perceived value as antecedents of the impacts of influential travel bloggers on their blog members' travel-related behavioral intentions and examined the mediating role of sense of virtual community (SOVC) among these relationships. The analysis results herein demonstrate that online social support, perceived value, and SOVC relate significantly to blog members' behavior intention. Furthermore, the influence of perceived value and SOVC on behavior intention are both respectively significant. With SOVC as a mediating variable, the CI indirect effect of the perceived value on travel intention did not include 0 , indicating an indirect relationship between these two variables. Referring to perceived values, the findings indicate that blog members perceive the influential travel blogs as offering epistemic value more than others. These findings have theoretical implications for social media and online interactionrelated literature and have critical business implications for customer-to-customer $(C 2 C)$ marketers to distinguish themselves within the expanding number of influential travel blogs.
\end{abstract}

() 2021 by the authors. Licensee SSBFNET, Istanbul, Turkey. This article is an open access article distributed under the terms and conditions of the Creative Commons Attribution (CC BY) license (http://creativecommons.org/licenses/by/4.0/).

\section{Introduction}

Media and technology have changed the way in which people gather information. Nowadays, blogging has become a popular form of user-generated content (UGC) and electronic word-of-mouth (Gurung \& Goswami, 2017). Many blogs provide commentary on a particular subject or topic, ranging from politics to sports. While some blogs function as personal online diaries, others operate more as online brand advertising for a particular individual or company (El Boukhari \& Sair, 2017). Blog writers form their special interest communities where they share thoughts, express opinions, debate ideas, and offer suggestions interactively. Moreover, blogs were recognized as a conversational and trusted resource that could help in making purchase decisions (Gao et al., 2019).

Influential travel blogs, in particular, are widely regarded as credible sources of information for tourists (Lodha \& Philip, 2019). Khan et al. (2017) argued that influential bloggers as representatives of virtual communities can have significant impact on public views and opinions. Similar to offline opinion leaders, influential bloggers can mediate messages and affect communities in the online environment, where messages can be disseminated rapidly and easily with a potentially virtual effect (Ishfaq et al., 2017). Such bloggers can be targeted for their marketing purposes, thus saving much marketing and advertising expenses (Tan \& Chang, 2016). The growth of travel blogs has attracted the attention of tourism researchers interested in the platform as a marketing tool and a source of information about tourists (Azariah, 2012). There is a growing recognition that influential travel bloggers facilitate powerful discussions that could affect tourist decisions and destination images and even reshape the communication networks

* Corresponding author. ORCID ID: 0000-0002-4285-3971

(C) 2021 by the authors. Hosting by SSBFNET. Peer review under responsibility of Center for Strategic Studies in Business and Finance. https://doi.org/10.20525/ijrbs.v10i4.1190 
previously dominated by traditional information suppliers (Tang et al., 2019). According to the Professional Travel Bloggers Association, over $80 \%$ of travel planning in 2018 was conducted on the internet, with $33 \%$ of US travelers using travel blogs for travel advice. With plentiful blog followers, influential travel bloggers have demonstrated their enormous marketing potential and have become an increasingly important platform for information exchange among tourists (Li, 2018). The few existing studies on travel blogs have highlighted the potential of travel blogs as sources of information regarding tourist experiences for consumer narrative analysis (Tseng et al. 2015; Chen \& Lin, 2015; Chandralal et al., 2015). Most research has been done on extracting from travel blogs data on destination image evaluation and tourist behavior, yet the effects of social support and perceived value on blog members' behavioral intention have received relatively little attention (Kapitan \& Silvera, 2016; Sano, 2018).

Additionally, sense of virtual community (SOVC) reflects the feeling that individual members have of belonging to an online social group; yet, few studies have illustrated the mediating role of SOVC in virtual communities of practices. Thus, this study aimed to examine how influential travel bloggers wield significant power over perceptions of blog members through social networking perspective. Online social support and perceived value were modeled in this study as antecedents of impacts of influential travel bloggers on travel intentions of their blog members. SOVC was proposed as a mediator of these relationships. These findings have theoretical implications for social commerce literature, and have critical business implications for customer to customer (C2C) marketers in distinguishing themselves among the expanding number of influential travel blogs.

This study aims to model online social support and perceived value as antecedents of the impacts of influential travel bloggers on their blog members' travel-related behavioral intentions, and examined the mediating role of sense of virtual community (SOVC) among these relationships

\section{Literature Review}

\section{Theoretical and Conceptual Background}

\section{The Role of Influential Travel Blogs on Travel Intention}

Travel blogs, which are usually updated and arranged chronologically in the form of a diary, are primarily used to publish personal travel stories and experiences online and to keep in touch with friends and relatives at home (Leung et al., 2013). Further motivations to write blogs include a need for self-expression and social interaction with like-minded people and a desire to share positive and negative experiences with other travelers. Through writing articles, bloggers have built their images as "masters" for online users or fans. Influential travel bloggers have become trusted online spokesmen due to their long-term efforts spent on certain travel knowledge (Tseng et al. 2015). Wang (2012) illustrated that travel related blogs play an influential role in individuals' travel intention starting from the initial information search to the choices considered and the final purchase decisions. An increasing number of influential travel bloggers are developing related attractive power by building their images to retain and draw in new blog members. Their one good word or positive comment can be extremely powerful and influential in encouraging travelers to accept their opinions about specific travel products and services (Chandralal et al., 2015).

\section{Role of online social support in virtual communities}

Social support is defined as the degree to which a person's basic social needs are gratified through interaction with others (Kaplan et al., 1977). With the development in information and communication technology (ICT), the boundary of social support is expanding from traditional face-to-face communication context to computer-mediated communication context (Kim \& Tussyadiah, 2013). Social support has recently received intensive attention from social commerce researchers, and it is suggested to be a critical indicator of participation and positive behaviors (Hu et al., 2019; Molinillo et al., 2020). Glimour et al. (2020) provide a comprehensive and systematic review of the state of the literature pertaining to Facebook-based online social support, which refers to the degree that individuals feel respected, supported and understood in online social groups (Tsai et al., 2018). Research into online social support has found that it can have various dimensions, and it satisfies an individual's physical, psychological, and cognitive needs (Huang et al., 2019; Sendra et al., 2019; Ellway et al., 2019; Tang et al., 2019; Frison \& Eggermont, 2016). In virtual environments, online community members share information and advice that help other members solve problems; they also experience social support when they feel cared for and helped by other members of the community (Doha et al., 2019). These relationships and ties between members provide emotional aid and information support, even though such online platforms comprised virtual strangers. Such online supports are core components of the social relationship network constructs (Tajvidi et al., 2020).

\section{Sense of virtual community (SOVC)}

Advancements in technology in the form of social media has created a research area focused on virtual community. As platforms for like-minded users to meet and share their interest-related information and experiences, the strategic role of virtual community is increasingly recognized (Ukpabi et al., 2019). A key concept associated with the sustainability of virtual communities is members' SOVC, which has been originally defined as the sense of belonging that members have toward their community, allowing them to convey beliefs and reach a mutual understanding, thereby demonstrating their commitment to the community (Chih et al., 2017). In virtual community studies, after Blanchard (2007) explored the concept of SOVC and claimed it as an important feature of virtual communities, its influence on consumers' purchase decisions has been evaluated by other studies (Hsieh and Tseng, 2018; Zhang et al., 2019). As Chih et al. (2017) suggested, understanding SOVC as an enabler for online community interaction has increased the 
value of this concept for social commerce research. Different research streams have examined SOVC and its antecedents (Lyu and Kim, 2020; Shim, 2020; Burnasheva et al., 2019; González-Anta et al., 2019; Zhang et al., 2019), while other studies on online communities found that community membership and influence processes play an important role in regulating community behavior (El-Manstrly et al., 2020; Hsieh \& Tseng, 2018). Exchanging support is one of the primary reasons for the existence of many online communities. The reception of social support within online communities will give members a stronger sense of community through meeting their informational, emotional, and even material needs (Molinillo et al., 2020). The norm of reciprocity motivates members to exchange support through sharing information, giving advice, offering reassurance, or cheering someone up (Gibbs et al., 2019). Previous studies have found that this collective process of support exchange would likely to increase members' sense of belonging to the entire group (Kaur et al., 2020; Wang et al., 2016). Thus, the following hypothesis is proposed:

\section{H1: Online social support is positively associated with SOVC of blog followers on influential travel blogs.}

\section{Perceived value of blog members}

Perceived value is related to the benefits users obtain from products or services. Zeithaml (1988) defined it as "consumers' overall assessment of the utility of a product or service based on perceptions of what is received and what is given". Perceived value represents the aggregation of benefits that the customer is seeking, expecting, or experiencing, as well as the possible undesired consequences resulting from them (Zheng et al., 2017). Prior research has empirically validated the effect of perceived value on user behavior in a variety of commercial contexts, such as traditional mall shopping (El-Adly \& Eid, 2017; Kesari \& Atulkar, 2016) and online shopping (Xiao et al., 2019; Sharma \& Klein, 2020). Taking the multidimensional perspective of value, Williams and Soutar (2009) developed a five-dimension model with value for money, emotional, social, and epistemic in the adventure-travel context. Besides measuring value in accordance to constructs listed above, value is also conceptualized and measured using different sets of dimensions proposed by other researchers (Chen \& Lin, 2019; Peng et al., 2019). For example, some extant studies have revealed that utilitarian and hedonic values are crucial for motivating purchase intention in social commerce context. (Gan \& Wang, 2017; Choi et al., 2018; Othman et al., 2019). Sharma and Klein (2020) framed perceived value using context-content and individualprofessional value scales for explaining the continuous usage of professional social network sites. Their findings highlight that hedonic perceived value is enhanced by the context-related conditional and epistemic value dimensions. Zhao and Lu (2012) identified four dimensions of perceived value for the microblogging service. They claimed that consumers who surf blogs seek both informational and social values. As $\mathrm{Wu}$ and $\mathrm{Li}$ (2018) stated, once followers' informational and social needs are satisfied, their relationship with the travel blog will be strengthened. By following influential blogs, people fulfill their needs for belongingness and cognition with those who have shared norms, values, and interests (Razi et al., 2016). People participating in virtual communities mainly hope to acquire useful knowledge to solve problems and gain expertise (Yahia et al., 2018). One of the major reasons for this phenomenon is the higher perceived credibility of influential bloggers' opinions compared with that of traditional tourist information sources (Hu et al., 2019). Thus, the following hypothesis is proposed:

\section{H2: Perceived value of followers towards influential travel blogs is positively associated with SOVC.}

\section{Travel intention}

For researchers, intention is a standard measurement for forecasting possible actual behavior. With the wide adoption of social commerce in travel and tourism industry, online channel has redefined travel intention as the consumers' willingness to purchase or reserve a travel product or service from social networking sites (Kornpitack \& Sornsaruht, 2019). Users in online forums and communities have emotional and informational support (Tajvidi et al., 2020). Such type of support increases the likelihood of community members to purchase and generates social relationships that make them feel welcome, listened to and cared for (Molinillo et al., 2020; $\mathrm{Hu}$ et al., 2019). As recent studies indicated, the social support that users receive from other members of online communities help them in making purchase decision, and affect positively affect their intentional behavior (Li, 2019; Yusuf \& Busalim, 2018). Thus, the following hypothesis is proposed:

\section{H3: Online social support is positively associated with travel intentions.}

Perceived value serves as a bridge linking the consumer's purchase intention and psychological behavior during decision-making (Peng et al., 2019). This view also supported the notion postulated by Shaw and Sergueeva (2019) that the higher the perceived value of a virtual community site, the stronger the behavioral intention of customers. Chen and Lin (2019) confirmed that social marketing activities has significant influence on perceived value, which in turn affects purchase intention. Thus, the following hypothesis is proposed:

\section{H4: Perceived value is positively associated with travel intention}

\section{H5: SOVC is positively associated with travel intention}

Vieno et al.(2007) proposed a mechanism whereby the effect of social support on psychological outcomes is mediated by that sense of community. Chang et al.(2016) provided a comprehensive model to illustrate the mediating role of SOVC in virtual communities of practices (VCoPs). Thus, hypotheses 5 and 6 are proposed as follows:

H6. SOVC mediates the influence of online social support on travel intentions. 


\section{H7. SOVC mediates the influence of perceived value on travel intentions}

\section{Research and Methodology}

\section{Sample and data collection}

This study designed an online questionnaire according to the hypotheses stated above. The sampling in this study were subscribers of one travel blog at least one or more. Blog followers of an online community were invited to complete the survey in the designated online questionnaire system. The questionnaire could only be submitted with all questions completed.

\section{Measures}

The measurement items for the four constructs, namely online social support, perceived value, SOVC, and behavioral intention, were selected from previous studies and rephrased to suit the context of the current study. Four items of online social support measures were adapted from Nick et al. (2018) and reworded. Items measuring perceived value were originally developed by Chen and Lin (2015) in a blog market context. Perceived value incorporates the five theoretical types of value, namely functional, social, emotional, epistemic, and conditional value. SOVC was measured using a modified version of sense of community (SCI) developed by Blanchard (2007). The resulting 9 items in the SOVC measure were introduced to assess support and identification in a travel blogging context in this study. Finally, A three-item scale measuring behavioral intention was designed by Kesari and Atulkar (2016) to measure blog members' intentions to purchase travel products posted in blogs. All items were measured using a seven-point Likert scale ranging from "strongly disagree" (1) to "strongly agree" (7). The descriptive information included participants' characteristics, such as gender, age, and usage behavior of using influential travel blogs, such as the number of blogs followed and time spent on surfing the blog.

\section{Data analysis}

This study examined the measurement model, the structure of the conceptual model, and each hypothesized path using structural equation modeling (SEM). The two-stage procedure of SEM was employed to conduct data analysis. The convergent validity was evaluated by Confirmatory Factor Analysis (CFA). The bootstrapping method was used for the path coefficients of latent variables to verify the mediating effect of the structural model (Bollen \& Stine, 1990).

\section{Results}

A total of 387 valid responses were returned for data analysis. Of the respondents, $40.3 \%$ were male and $59.7 \%$ were female. $32 \%$ of the respondents were aged 21 to 30 years, $30.4 \%$ were aged 31 to 40 years. In terms of blog usage behavior, $36.7 \%$ of respondents spent 3 to 5 hours a day surfing the blogs, $41.4 \%$ followed one to two blogs, $88.4 \%$ follow travel blogs via FB and IG (Table I).

Table 1: Respondents' Demographic Profiles.

\begin{tabular}{|c|c|c|c|}
\hline Demographic profiles & Statistics & $\begin{array}{l}\text { Frequency } \\
(\mathbf{N}=387)\end{array}$ & Percent \\
\hline \multirow[t]{2}{*}{ Gender } & Male & 156 & 40.3 \\
\hline & Female & 231 & 59.7 \\
\hline \multirow[t]{6}{*}{ Age (years) } & $\leq 20$ & 27 & 6.9 \\
\hline & $21-30$ & 124 & 32.0 \\
\hline & $31-40$ & 118 & 30.4 \\
\hline & $41-50$ & 66 & 17.0 \\
\hline & $51-60$ & 39 & 10.1 \\
\hline & $>60$ & 13 & 3.3 \\
\hline \multirow{6}{*}{$\begin{array}{l}\text { Time spent on surfing blogs } \\
\text { (hours) }\end{array}$} & $<1$ & 38 & 9.8 \\
\hline & $1-2$ & 87 & 22.5 \\
\hline & $3-5$ & 142 & 36.7 \\
\hline & $6-9$ & 74 & 19.1 \\
\hline & $10-12$ & 15 & 3.9 \\
\hline & $>12$ & 31 & 8.0 \\
\hline \multirow[t]{3}{*}{ Numbers of blog followed } & $1-2$ & 160 & 41.3 \\
\hline & $3-5$ & 109 & 28.2 \\
\hline & 6 or more & 118 & 30.5 \\
\hline \multirow[t]{3}{*}{ Sources of subscribing blogs } & Social media (FB, IG.) & 342 & 88.4 \\
\hline & Live stream & 19 & 4.9 \\
\hline & TV program & 26 & 6.7 \\
\hline
\end{tabular}

Tables 2 and 3 present statistical analysis results. As can be seen. Cronbach's alphas all exceeded .7, indicating that each variable has good (> .79) or excellent (> .89) convergent validity (Devellis, 1991). Moreover, the average variance extracted (AVE) value 
also exceeded .5, and the square root of AVE of each factor was larger than the normalized correlation coefficient outside the diagonal line, revealing good discriminant validity of all variables (Fornell \& Larcker, 1981).

Table 2: Standardized Loadings and Reliabilities

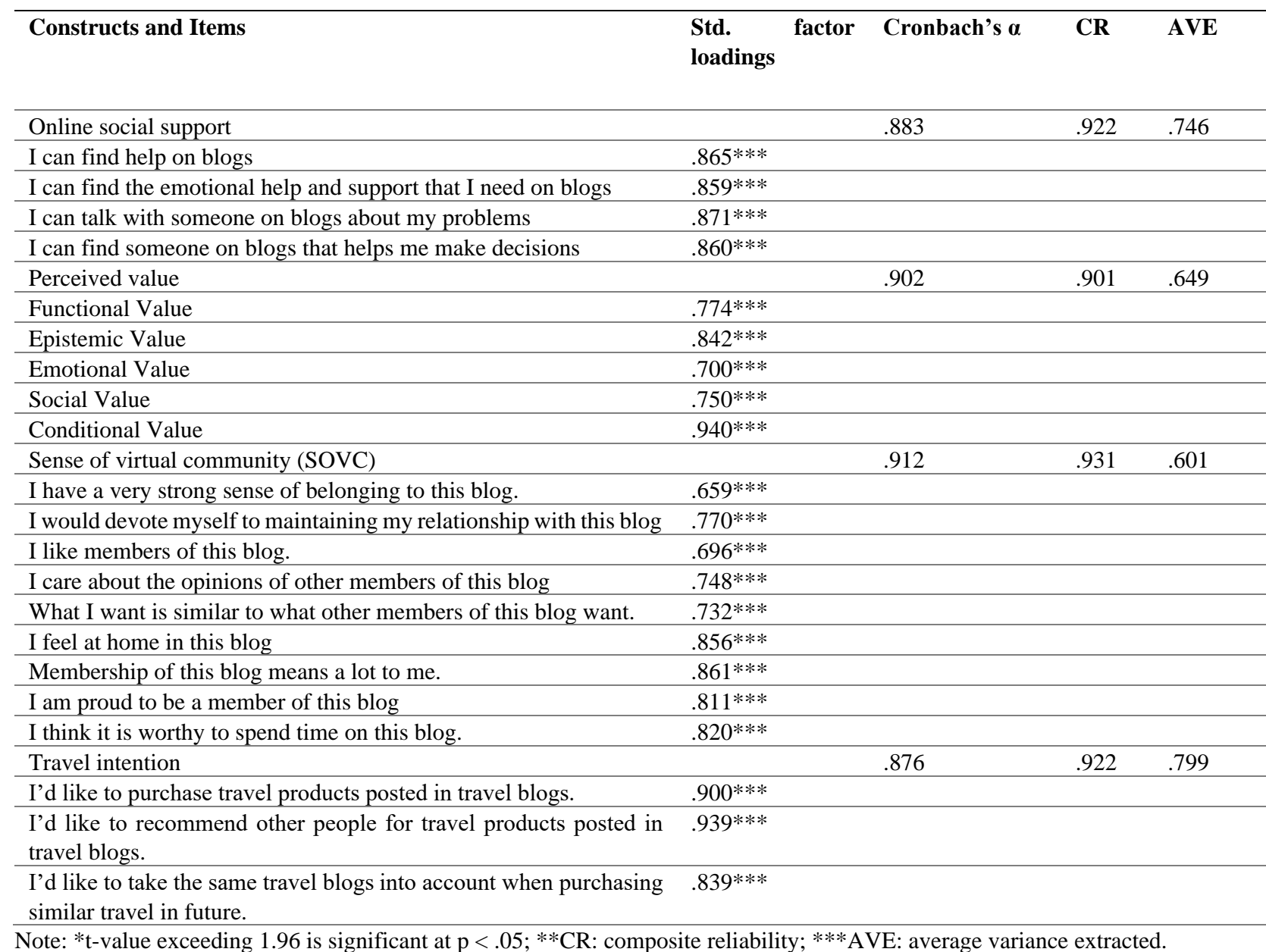

Note: $*$ t-value exceeding 1.96 is significant at $\mathrm{p}<.05 ; * * \mathrm{CR}$ : composite reliability; $* * * A V E$ : average variance extracted.

Table 3: Descriptive Statistics and Correlation of Study Variables.

\begin{tabular}{|c|c|c|c|c|c|c|c|}
\hline \multirow[t]{2}{*}{ Constructs } & \multirow[t]{2}{*}{ Mean } & \multirow[t]{2}{*}{ SD } & \multirow[t]{2}{*}{ AVE } & \multicolumn{4}{|c|}{ Discriminant validity } \\
\hline & & & & OSS & PV & SOVC & TI \\
\hline OSS & 5.576 & 1.005 & .746 & .864 & & & \\
\hline PV & 5.681 & .782 & .649 & .717 & .806 & & \\
\hline SOVC & 5.666 & .877 & .601 & .758 & .726 & .775 & \\
\hline TI & 5.378 & 1.193 & .799 & .643 & .570 & .670 & .894 \\
\hline
\end{tabular}

Note: Diagonal elements (shaded) are the square root of AVE.

OSS = online social support; $\mathrm{PV}=$ perceived value; $\mathrm{SOVC}=$ sense of virtual community; $\mathrm{TI}=$ Travel intention.

The chi-square statistical results on the approximate goodness-fit-indices of this conceptual model $(\chi 2=548.898, \mathrm{p}<.000 ; \mathrm{df}=183$; $\mathrm{CMIN} / \mathrm{DF}(\chi 2 / \mathrm{df})=2.999)$ showed that the ratio of minimum discrepancy divided by its degrees of freedom approximated 1 and did not exceed 3 (McIver \& Carmines, 1981). According to Bollen and Stine (1990), the chi-square statistic $(\chi 2)$ is sensitive to sample size; hence, it is necessary to look at other model fit indices that also support goodness-of-fit (e.g., CFI, TLI, RMSEA). All alternative indices were also in line with the acceptable research standard; TLI, IFI, and CFI were all above $0.9(\mathrm{TLI}=.937, \mathrm{IFI}=.946$, CFI $=$ $.945)$, AGFI $=.844$, GFI $=.877$, all exceeding 0.8 ; and RMSEA $=.072$, less than .08 . Thus, these indices revealed an acceptable fit for the research model.

Table 4 showed the significance of each hypothesized path. As can be seen, except for $\mathrm{H} 4$, all the paths in the research model were significant at either .001 or .05 level. Specifically, the direct relationship between online social support and SOVC $(\beta=0.512$, p < 0.001 ) was positive; thus, H1 was supported. Perceived value also had a positive association with $\operatorname{SOVC}(\beta=.37, \mathrm{p}<0.001)$; hence, 
H2 was supported. Online social support was found to have positive impact on travel intention $(\beta=0.265, \mathrm{p}<0.05)$; thus, H3 was supported. However, perceived value was found to have no significant impact on travel intention $(\beta=.100, p<.01)$; thus, H4 was rejected. SOVC was found to positively associated with travel intention $(\beta=0.414, p<0.05)$; hence, H5 was supported.

With SOVC as a mediating variable, the CI indirect effect of perceived value on purchase intention did not include 0 , indicating an indirect relationship between the two variables. As shown in Table 4, SOVC has a partial mediating role in the relationships between online social support, perceived value, and travel intention; thus, $\mathrm{H6}$ and $\mathrm{H7}$ are empirically supported.

Table 4: Summary of results on hypothesis testing

\begin{tabular}{|c|c|c|c|c|c|}
\hline \multicolumn{2}{|c|}{ Hypothesis } & \multirow[t]{2}{*}{ Coefficient } & \multicolumn{2}{|c|}{ Bias-Corrected $95 \%$ CI } & \multirow[t]{2}{*}{ Supported } \\
\hline & & & Lower & Upper & \\
\hline H1 & $\mathrm{OSS} \rightarrow \mathrm{SOVC}$ & .512 & .272 & .548 & $\mathrm{Y}$ \\
\hline $\mathbf{H} 2$ & $\mathrm{PV} \rightarrow \mathrm{SOVC}$ & .370 & .235 & .599 & $\mathrm{Y}$ \\
\hline H3 & $\mathrm{OSS} \rightarrow \mathrm{TI}$ & .265 & .097 & .563 & $\mathrm{Y}$ \\
\hline H4 & $\mathrm{PV} \rightarrow \mathrm{TI}$ & .100 & -.103 & .505 & $\mathrm{~N}$ \\
\hline H5 & $\mathrm{SOVC} \rightarrow \mathrm{TI}$ & .414 & .368 & .953 & $\mathrm{Y}$ \\
\hline H6 & $\mathrm{OSS} \rightarrow \mathrm{SOVC} \rightarrow \mathrm{TI}$ & .212 & .137 & .449 & $\mathrm{Y}$ \\
\hline H7 & $\mathrm{PV} \rightarrow \mathrm{SOVC} \rightarrow \mathrm{TI}$ & .153 & .130 & .451 & $\mathrm{Y}$ \\
\hline
\end{tabular}

Note: A bootstrapping method with 5000 sample size generated at 95\% confidence interval (CI) was adopted to test the significance of indirect effects. OSS = online social support; PV = perceived value; SOVC = sense of virtual community; $\mathrm{TI}=\mathrm{Travel}$ intention.

\section{Conclusions}

This study aims to model online social support and perceived value as antecedents of the impact of influential travel bloggers on their followers' travel intentions, and to examined the mediating role of SOVC in these relationships. The findings indicated that blog followers with a strong sense of online social support and perceived value could have a strong sense of virtual community, which is more likely to affect their travel intention.

At the theoretical level, this study sheds light on the mechanism of social commerce in blog platforms. While social media has been extensively studied, specific nuances associated with influential travel blogs have not received sufficient scholarly attention. This study shows that relational social networks of blog followers' participatory engagement induce positive celebrity-dominant marketing effects.

This study conceptualized that online social support exerts significant influence on SOVC and travel intention, which is similar to the findings of prior studies (Khan et al., 2017; Yahia et al., 2018). People join virtual communities to exchange both information and social support, revealing that high intensity of online social support led to increased perception of SOVC of blog followers. Moreover, the positive association between strengthening of SOVC and travel intention of blog followers indicated that the main effects of influential travel bloggers are not only the participation of people, but also their direct influence on various spheres of people's behaviors in a more emotional and interactive way. These results are consistent with the social identity theory, which proposes that social needs facilitate people's identification with a group (Hogg et al., 1995).

Another theoretical contribution of this study is the finding that perceived value is not a strong predictor for travel intention. This is not in line with the results obtained by Yang and Shim (2020) and Chen and Lin (2019), which found perceived value to be a significant determinant of customers' behavioral intention. The present findings demonstrated that when involved in sharing information, discussing travel experiences, or seeking solutions to problems during travel, blog members perceive the community as offering more epistemic value. A possible explanation is that tourists when browsing influential travel blogs pay more attention to perceived value on acquisition of information and learning of travel experience. By doing so, they seem to temporarily satisfy travel in the virtual world through visualization and text reading, so as to reduce perceived travel risk in the future as they travel. Therefore, it does not have a significant impact on travel intention.

This study also offers insight for marketing practitioners. First, gaining and searching travel information through blog browsing is an essential form of participation, and given the linkage with SOVC. In the era of social media, consumers are overloaded with information. As this study indicated, information value for travel blog followers is sophisticated and multi-layered. Thus, influential travel bloggers should contribute to the positive community-level atmosphere while simultaneously fulfilling followers' own information-related needs and establishing a sense of belonging. Moreover, the positive effect of SOVC on travel intention shows that influential travel blogs are used by followers as platforms for gaining psychological benefits, which in turn foster their loyalty to blogs. It is, therefore, recommended that influential travel bloggers should provide useful, accurate, relevant and easy-to- 
understand travel information. In this way, followers are more likely to subscribe the blogs, which would eventually affect their decision-making. Second, influential travel bloggers regard themselves as online celebrities and personal brands. In the increasingly valued fan economy nowadays, influential travel bloggers must focus on shaping their own celebrity charm and become celebrity endorsements for travel destinations. Establishing a loyal fan relationship from interacting with blog subscribers creates a good sense of community and trust, which in turn affects consumers' purchase behavior of travel products. Overall, marketing tools and strategies have fundamentally changed since the appearance of social media (Chen \& Lin, 2019), most influential travel bloggers should focus on managing a brand community to create a business advantage.

Although the findings provide significant theoretical and practical insights, a number of limitations should be acknowledged. First, the proposed theoretical model was evaluated by this empirical study on influential travel blogs. However, a variety of new social media platforms such as Pinterest, tweets, and live steaming implied that future studies should consider the characteristics of users. For example, twitter users and livestreaming users may behave differently in terms of their purchase intention. Second, future studies can focus on examining the effects of other variables, such as perceived credibility, privacy attitude and perceived security, on consumers' intentions for making travel purchase or bookings via these new social media platforms. Last, the survey of this study was conducted on certain influential travel blogs in Taiwan due to accessibility and time constraints. Therefore, the results from this study cannot be generalized beyond Taiwan. Similar studies should be replicated to increase the generalizability of the findings. For example, future studies can explore the possible variation in determining consumer behavior across different ethnic groups and cultures.

\section{References}

Azariah, D. R. (2012). When travel meets tourism: Tracing discourse in Tony Wheeler's blog. Critical Studies in Media Communication, 29(4), 275-291. https://doi.org/10.1080/15295036.2011.574640

Blanchard, A. L. (2007). Developing a sense of virtual community measure. Cyberpsychology \& Behavior: The Impact of the Internet, Multimedia and Virtual Reality on Behavior and Society, 10(6), 827-830. https://doi.org/10.1089/cpb.2007.9946

Bollen, K. A., \& Stine, R. (1990). Direct and indirect effects: Classical and bootstrap estimates of variability. Sociological Methodology, 20, 115. https://doi.org/10.2307/271084

Burnasheva, R., Suh, Y. G., \& Villalobos-Moron, K. (2019). Sense of community and social identity effect on brand love: Based on the online communities of a luxury fashion brands. Journal of Global Fashion Marketing, 10(1), 50-65. https://doi.org/10.1080/20932685.2018.1558087

Chandralal, L., Rindfleish, J., \& Valenzuela, F. (2015). An application of travel blog narratives to explore memorable tourism experiences. Asia Pacific Journal of Tourism Research, 20(6), 680-693. https://doi.org/10.1080/10941665.2014.925944

Chang, H. H., Hsieh, P. H., \& Fu, C. S. (2016). The mediating role of sense of virtual community. Online Information Review, 40(7), 882-899. https://doi.org/10.1108/OIR-09-2015-0304

Chen, S. C., \& Lin, C. P. (2015). The impact of customer experience and perceived value on sustainable social relationship in blogs: An empirical study. Technological Forecasting and Social Change, 96, 40-50. https://doi.org/10.1016/j.techfore.2014.11.011

Chen, S. C., \& Lin, C. P. (2019). Understanding the effect of social media marketing activities: The mediation of social identification, perceived value, and satisfaction. Technological Forecasting and Social Change, 140, 22-32. https://doi.org/10.1016/j.techfore.2018.11.025

Chih, W. H., Hsu, L. C., \& Liou, D. K. (2017). Understanding virtual community members' relationships from individual, group, and social influence perspectives. Industrial Management and Data Systems, 117(6), 990-1010. https://doi.org/10.1108/IMDS-03-2016-0119

Choi, M., Law, R., \& Heo, C. Y. (2018). An investigation of the perceived value of shopping tourism. Journal of Travel Research, 57(7), 962-980. https://doi.org/10.1177/0047287517726170

Doha, A., Elnahla, N., \& McShane, L. (2019). Social commerce as social networking. Journal of Retailing and Consumer Services, 47, 307-321. https://doi.org/10.1016/j.jretconser.2018.11.008

El Boukhari, M., \& Sair, A. (2017). Travel blogs and perceived destination image: theoretical background. World Scientific News, 2(67), 189-200. Retrieved from https://www.infona.pl/resource/bwmeta1.element.psjd-8b235ea6-3624-44e9-b2f4af55bfa0c7d6/tab/summary

El-Adly, M. I., \& Eid, R. (2017). Dimensions of the perceived value of malls: Muslim shoppers' perspective. International Journal of Retail and Distribution Management, 45(1), 40-56. http://doi.org/10.1108/IJRDM-12-2015-0188

Ellway, D., Reilly, R., Le Couteur, A., \& Ward, J. (2019). Exploring how people affected by methamphetamine exchange social support through online interactions on Facebook: content analysis. JMIR Mental Health, 6(10), e14011. https://doi.org/10.2196/14011

El-Manstrly, D., Ali, F., \& Steedman, C. (2020). Virtual travel community members' stickiness behaviour: How and when it develops. International Journal of Hospitality Management, 88, 102535. https://doi.org/10.1016/j.ijhm.2020.102535

Fornell, C., \& Larcker, D. F. (1981). Evaluating structural equation models with unobservable variables and measurement error. Journal of Marketing Research, 18(1), 39-50. Retrieved from https://www.jstor.org/stable/pdf/3150979.pdf?casa_token=7Li7zL2lbjYAAAAA:KLGOCJW21yKzi0cqpPheEDJBEBDbY 0cfmpLOSReJO_WuSNmMgIv3PP4yZQAOfJL3VTY-_4YwH_7WVlp5xT-0rfR3IcYqsXIEY0v2g65cZ8Gj-IHpgQ 
Frison, E., \& Eggermont, S. (2016). Exploring the relationships between different types of Facebook use, perceived online social support, and adolescents' depressed mood. Social Science Computer Review, 34(2), 153-171. https://doi.org/10.1177/0894439314567449

Gan, C., \& Wang, W. (2017). The influence of perceived value on purchase intention in social commerce context. Internet Research, 27(4), 772-785. https://doi.org/10.1108/IntR-06-2016-0164

Gao, Y., Ye, C., Zhong, X., Wu, L., \& Liu, Y. (2019). Extracting Spatial Patterns of Intercity Tourist Movements from Online Travel Blogs. Sustainability, 11(13), 3526. https://doi.org/10.3390/su11133526

Gibbs, J. L., Kim, H., \& Ki, S. (2019). Investigating the role of control and support mechanisms in members' sense of virtual community. Communication Research, 46(1), 117-145. https://doi:10.3390/su11133526

Gilmour, J., Machin, T., Brownlow, C., \& Jeffries, C. (2020). Facebook-based social support and health: A systematic $\begin{array}{llllll}\text { review. Psychology } & \text { of } & \text { Popular } & \text { Media, 9(3), } & 328 . & \text { Retrieved }\end{array}$ https://eprints.usq.edu.au/37715/1/Facebook\%20Social\%20Support\%20Review\%20PsychPopCulture\%20Manuscript $\% 28$ Draft\%29.pdf

González-Anta, B., Orengo, V., Zornoza, A., Peñarroja, V., \& Martínez-Tur, V. (2021). Understanding the sense of community and continuance intention in virtual communities: the role of commitment and type of community. Social Science Computer Review, 39(3), 335-352. https://doi.org/10.1177/0894439319859590

Gurung, D. J., \& Goswami, C. (2017). User Generated Content on Sikkim as an Image Formation Agent: A Content Analysis of Travel Blogs. International Journal of Hospitality \& Tourism Systems, 10(2), 47-57.

Hogg, M. A., Terry, D. J., \& White, K. M. (1995). A tale of Two theories: A critical comparison of identity theory with social identity theory. Social Psychology Quarterly, 58, 255-269. https://doi.org/10.2307/2787127

Hsieh, J. K., \& Tseng, C. Y. (2018). Exploring Social influence on hedonic buying of digital goods—online games virtual items. Journal of Electronic Commerce Research, 19(2), 164-185. Retrieved from http://www.jecr.org/sites/default/files/2018vol19no2_Paper4.pdf

Hu, X., Chen, X., \& Davison, R. M. (2019). Social support, source credibility, social influence, and impulsive purchase behavior in social commerce. International Journal of Electronic Commerce, 23(3), $297-327$. https://doi.org/10.1080/10864415.2019.1619905

Huang, K. Y., Chengalur-Smith, I., \& Pinsonneault, A. (2019). Sharing is caring: Social support provision and companionship activities in healthcare virtual support communities. MIS Quarterly, 43(2), $395-423$. https://doi.org/10.25300/MISQ/2019/13225

Ishfaq, U., Khan, H. U., \& Iqbal, K. (2017). Identifying the Influential Bloggers: A modular approach based on Sentiment Analysis. Journal of Web Engineering, $16(5 \quad \& \quad 6), \quad 505-523 . \quad$ Retrieved from https://www.riverpublishers.com/journal/journal_articles/RP_Journal_1540-9589_1655.pdf

Kapitan, S., \& Silvera, D. H. (2016). From digital media influencers to celebrity endorsers: attributions drive endorser effectiveness. Marketing Letters, 27(13), 553-567. https://doi.org/10.1007/s11002-015-9363-0

Kaplan, B. H., Cassel, J. C., \& Gore, S. (1977). Social support and health. Medical care, 15(5), 47-58.

Kaur, H., Paruthi, M., Islam, J., \& Hollebeek, L. D. (2020). The role of brand community identification and reward on consumer brand engagement and brand loyalty in virtual brand communities. Telematics and Informatics, 46, 1-12. https://doi.org/10.1016/j.tele.2019.101321

Kesari, B., \& Atulkar, S. (2016). Satisfaction of mall shoppers: A study on perceived utilitarian and hedonic shopping values. Journal of Retailing and Consumer Services, 31, 22-31. https://doi.org/10.1016/j.jretconser.2016.03.005

Khan, H. U., Daud, A., Ishfaq, U., Amjad, T., Aljohani, N., Abbasi, R. A., \& Alowibdi, J. S. (2017). Modelling to identify influential bloggers in the blogosphere: A survey. Computers in Human Behavior, 68, 64-82. https://doi.org/10.1016/j.chb.2016.11.012

Kim, J., \& Tussyadiah, I. P. (2013). Social networking and social support in tourism experience: The moderating role of online selfpresentation strategies. Journal of Travel \& Tourism Marketing, 30(1-2), $78-92$. https://doi.org/10.1080/10548408.2013.751220

Kornpitack, P., \& Sornsaruht, P. (2019). Intention to purchase travel online: A SEM analysis. European Research Studies Journal, O(3), 246-260. Retrieved from https://www.um.edu.mt/library/oar/bitstream/123456789/47668/1/Intention\%20to\%20Purchase\%20Travel\%20Online_\%20 A\%20SEM\%20Analysis.pdf

Leung, D., Law, R., Van Hoof, H., \& Buhalis, D. (2013). Social media in tourism and hospitality: A literature review. Journal of travel \& tourism marketing, 30(1-2), 3-22. https://doi.org/10.1080/10548408.2013.750919

Li, C. Y. (2019). How social commerce constructs influence customers' social shopping intention? An empirical study of a social commerce website. Technological Forecasting and Social Change, 144, 282-294. https://doi.org/10.1016/j.techfore.2017.11.026

Li, R. (2018). The secret of internet celebrities: A qualitative study of online opinion leaders on weibo. [Paper presentation]. In Proceedings of the 51st Hawaii International Conference on System Sciences (pp.533-542). https://doi.org/10.24251/HICSS.2018.068

Lodha, R., \& Philip, L. (2019). Impact of Travel Blogs and Vlogs on the Decision Making Among the Students of Bangalore. International Journal of Scientific Research and Review, 7(3), 2279-2543. 
Lyu, J., \& Kim, J. (2020). Antecedents of social media induced retail commerce activities: Impact of brand-consumer relationships and psychological sense of community. Journal of Interactive Advertising, 1-34. https://doi.org/10.1080/15252019.2020.1769513

McIver, J., \& Carmines, E. G. (1981). Unidimensional Scaling. Sage.

Molinillo, S., Anaya-Sánchez, R., \& Liébana-Cabanillas, F. (2020). Analyzing the effect of social support and community factors on customer engagement and its impact on loyalty behaviors toward social commerce websites. Computers in Human Behavior, 108, 105980. https://doi.org/10.1016/j.chb.2019.04.004

Nick, E. A., Cole, D. A., Cho, S. J., Smith, D. K., Carter, T. G., \& Zelkowitz, R. L. (2018). The Online Social Support Scale: Measure development and validation. Psychological Assessment, 30(9), 1127-1143. https://doi.org/10.1037/pas0000558

Othman, A. K., Hassan, L. F., Hamzah, M. I., Razali, A. R., Saim, M. A., Ramli, M. S., \& Azhar, M. A. (2019). The influence of social commerce factors on customer intention to purchase. Asian Themes in Social Sciences Research, 3(1), 1-10. https://doi.org/10.33094/journal.139.2019.31.1.10

Peng, L., Zhang, W., Wang, X., \& Liang, S. (2019). Moderating effects of time pressure on the relationship between perceived value and purchase intention in social E-commerce sales promotion: Considering the impact of product involvement. Information and Management, 56(2), 317-328. https://doi.org/10.1016/j.im.2018.11.007

Razi, F. A. M., Sufandi, N. A., Kolit, S. S., Kamal, S. B. M., Abdullah, D., \& Azmi, A. (2016). Factors influencing acceptance and prolong usage of travel blogs: The imperative role of hedonism. International Academic Research Journal of Business and Technology, 2(2), 112-117.

Sano, K. (2018). Exploring how travel blogs influence solo Chinese tourists to visit Japan: A netnographic study of Chinese tourist's travel blogs. CAUTHE 2018: Get Smart: Paradoxes and Possibilities in Tourism, Hospitality and Events Education and Research, 728.

Sendra, A., Farré, J., \& Vaagan, R. W. (2019). Seeking, sharing, and co-creating: A systemic review of the relation between social support theory, social media use and chronic diseases. Social Theory \& Health, 18(4), 317-339. https://doi.org/10.1057/s41285-019-00106

Sharma, V. M., \& Klein, A. (2020). Consumer perceived value, involvement, trust, susceptibility to interpersonal influence, and intention to participate in online group buying. Journal of Retailing and Consumer Services, 52, 101946. https://doi.org/10.1016/j.jretconser.2019.101946

Shaw, N., \& Sergueeva, K. (2019). The non-monetary benefits of mobile commerce: Extending UTAUT2 with perceived value. International Journal of Information Management, 45, 44-55. https://doi.org/10.1016/j.ijinfomgt.2018.10.024

Shim, A. Y. (2020). Antecedents of microblogging users' purchase intention toward celebrities' merchandise: Perspectives of virtual community and fan economy. Journal of Psychological Research, 2(2), 11-26. https://doi.org/10.30564/jpr.v2i2.1646

Tajvidi, M., Richard, M.-O., Wang, Y., \& Hajli, N. (2020). Brand co-creation through social commerce information sharing: The role of social media. Journal of Business Research, 121, 476-486. https://doi.org/10.1016/j.jbusres.2018.06.008

Tan, W. K., \& Chang, Y. G. (2016). Place familiarity and attachment: moderators of the relationship between readers' credibility assessment of a travel blog and review acceptance. Journal of Travel \& Tourism Marketing, 33(4), 453-470. https://doi.org/10.1080/10548408.2015.1064059

Tang, Y., Zhong, M., Qin, H., Liu, Y., \& Xiang, L. (2019). Negative word of mouth about foreign lands: Dimensions of the shared discomforts narrated in travel blogs. Journal of Global Scholars of Marketing Science, 29(3), 311-329. https://doi.org/10.1080/21639159.2019.1622436

Tsai, S., Crawford, E., \& Strong, J. (2018). Seeking virtual social support through blogging: a content analysis of published blog posts written by people with chronic pain. Digital Health, 4. 2055207618772669. https://doi.org/10.1177/2055207618772669

Tseng, C., Wu, B., Morrison, A. M., Zhang, J., \& Chen, Y. C. (2015). Travel blogs on China as a destination image formation agent: A qualitative analysis using Leximancer. Tourism Management, 46, 347-358. https://doi.org/10.1016/j.tourman.2014.07.012

Ukpabi D., Karjaluoto H., Olaleye S., Mogaji E. (2019) Influence of Offline Activities and Customer Value Creation on Online Travel Community Continuance Usage Intention. In: Pesonen J., Neidhardt J. (eds) Information and Communication Technologies in Tourism 2019. Springer, Cham. https://doi.org/10.1007/978-3-030-05940-8_35

Vieno, A., Santinello, M., Pastore, M., \& Perkins, D. D. (2007). Social support, sense of community in school, and self-efficacy as resources during early adolescence: an integrative model. American Journal of Community Psychology, 39(1-2), 177-190. https://doi.org/10.1007/s10464-007-9095-2

Wang, H. Y. (2012). Investigating the determinants of travel blogs influencing readers' intention to travel. The Service Industries Journal, 32(2), 231-255. https://doi.org/10.1080/02642069.2011.559225

Wang, S., Tong, J., \& Zhou, D. (2016). Study on the influence path of brand virtual community interaction on customer loyalty. Open Journal of Business and Management, 4(1), 138. 10.4236/ojbm.2016.41016

Williams, P., \& Soutar, G. N. (2009). Value, satisfaction and behavioral intentions in an adventure tourism context. Annals of Tourism Research, 36(3), 413-438. https://doi.org/10.1016/j.annals.2009.02.002

Wu, Y. L., \& Li, E. Y. (2018). Marketing mix, customer value, and customer loyalty in social commerce: A stimulus-organismresponse perspective. Internet Research, 28(1), 74-104. https://doi.org/10.1108/IntR-08-2016-0250

Xiao, L., Guo, F., Yu, F., \& Liu, S. (2019). The effects of online shopping context cues on consumers' purchase intention for crossborder E-Commerce sustainability. Sustainability, 11(10), 2777. https://doi.org/10.3390/su11102777 
Yahia, I. B., Al-Neama, N., \& Kerbache, L. (2018). Investigating the drivers for social commerce in social media platforms: Importance of trust, social support and the platform perceived usage. Journal of Retailing and Consumer Services, 41, 1119. https://doi.org/10.1016/j.jretconser.2017.10.021

Yusuf, A. S., \& Busalim, A. H. (2018). Influence of e-WOM engagement on consumer purchase intention in social commerce. Journal of Services Marketing, 32(4), 492-504. https://doi.org/10.1108/JSM-01-2017-0031

Zeithaml, V. A. (1988). Consumer perceptions of price, quality, and value: A means-end model and synthesis of evidence. The Journal of Marketing, 52(3), 2-22. https://doi.org/10.1177/002224298805200302

Zhang, H., Wang, Z., Chen, S., \& Guo, C. (2019). Product recommendation in online social networking communities: An empirical study of antecedents and a mediator. Information and Management, 56(2), 185-195. https://doi.org/10.1016/j.im.2018.05.001

Zhao, L., \& Lu, Y. (2012). Enhancing perceived interactivity through network externalities: An empirical study on micro-blogging service satisfaction and continuance intention. Decision Support Systems, 53(4), 825-834. https://doi.org/10.1016/j.dss.2012.05.019

Zheng, C., Yu, X., \& Jin, Q. (2017). How user relationships affect user perceived value propositions of enterprises on social commerce platforms. Information Systems Frontiers, 19(6), 1261-1271. https://doi.org/10.1007/s10796-017-9766-y

Publisher's Note: SSBFNET stays neutral with regard to jurisdictional claims in published maps and institutional affiliations.

\section{(ब) (1)}

(C) 2021 by the authors. Licensee SSBFNET, Istanbul, Turkey. This article is an open access article distributed under the terms and conditions of the Creative Commons Attribution (CC BY) license (http://creativecommons.org/licenses/by/4.0/).

International Journal of Research in Business and Social Science (2147-4478) by SSBFNET is licensed under a Creative Commons Attribution 4.0 International License. 